\title{
The socially and spatially bounded relationships of entrepreneurial activity: Olav Sorenson-recipient of the 2018 Global Award for Entrepreneurship Research
}

\author{
Annika Rickne • Martin Ruef • Karl Wennberg
}

Published online: 13 July 2018

(C) The Author(s) 2018

\begin{abstract}
This article reviews the academic contributions of Olav Sorenson, recipient of the 2018 Global Award for Entrepreneurship Research. His work has advanced scholarly understanding of how entrepreneurship and innovation are strongly embedded in socially and spatially bounded relationships. Based on meticulous empirical studies using a broad range of methods, he has challenged conventional models of new firms' location choices, explained patterns of and determinants of knowledge diffusion, and considered how social networks can lead to economic advantages. This article discusses Sorenson's work specifically focusing on three themes - (i) the geography of entrepreneurial activity, (ii) social capital, and (iii) the evolution of learning and innovation - highlighting scholarly contributions and insights for management practice and public policy.
\end{abstract}

Keywords Global Award for Entrepreneurship Research · Geography of entrepreneurship · Social capital $\cdot$ Learning $\cdot$ Innovation

\footnotetext{
A. Rickne

Linköping University, Linköping, Sweden

e-mail: annika.rickne@liu.se

M. Ruef

Duke University, Durham, NC, USA

e-mail: martin.ruef@duke.edu

K. Wennberg $(\bowtie)$

Institute for Analytical Sociology (IAS), Linköping University,

Linköping, Sweden

e-mail: karl.wennberg@liu.se
}

JEL classifications $\mathrm{M} 13 \cdot \mathrm{L} 25 \cdot \mathrm{R} 11 \cdot \mathrm{R} 12 \cdot \mathrm{R} 30 \cdot 03$

\section{Introduction}

Olav Sorenson is Professor of Management at the Yale School of Management. He is highly prolific in the area of entrepreneurship and innovation and has published more than 60 papers since receiving his Ph.D. at Stanford University in 1997. In 2018, he was awarded of the Global Award for Entrepreneurship Research, the most prestigious international research prize related to entrepreneurship. This article reviews the academic contributions of Sorenson and sets them in relation to crucial themes and research puzzles in entrepreneurship research.

Sorenson's outstanding contributions build on the notion that entrepreneurial activity and innovation are strongly embedded in socially and spatially bounded relationships. By combining insights from sociology, economic geography, and economics, he has provided new understandings which challenge established views on the microeconomic foundations of location choice, knowledge diffusion, and interactions among economic agents. In this article, we summarize his major research contributions under three themes.

First, relating to the geography of entrepreneurial activity, a long-standing research question is why organizations of similar types are inclined to co-locate. Since the late nineteenth century, social scientists have pointed towards shared factor markets and infrastructure, as well as the potential for knowledge spillovers between 
producers, as central mechanisms. At the same time, colocation by nature means that there are more organizations of the same type competing for resources in the same area. In meticulous analyses of investment data, Sorenson has shown that US venture capitalists' investments are spatially and industrially restricted due to their personal and professional networks. Moreover, the localisation of new ventures in emerging sectors has been shown to strongly correlate with the whereabouts of venture capital activity, as well as with proximity to 'liquidity inducing events' such as initial public offerings or firm acquisitions. On the microlevel, Sorenson and his co-authors have argued and shown that new firms' location choices are strongly determined by entrepreneurs' personal affiliations to friends and family, leading a large number of new ventures to locate 'close to home', and these businesses often seem to derive performance benefits in doing so.

Sorenson's research has also challenged some of the received wisdom in studies of spatial agglomeration. By pointing out the paradox that agglomeration induces intensified competition, as well as potential benefits, Sorenson and colleagues have placed traditional findings on performance advantages for mature enterprises into question. In particular, Sorenson has helped advanced a long-standing debate in economic geography by distinguishing agglomeration benefits for new firms from agglomeration costs for mature companies.

Second, Sorenson's research has addressed the link between social capital and entrepreneurial activity. Scrutinizing the entrepreneurial process, he has established an approach to studying the origin and evolution of networks, and how social networks can affect investments, acquisitions, and firm performance. He shows the constraining effects of networks, insofar as repeated collaboration within pre-existing relationships may bring additional resources at lower cost and spur the merger of related firms, but may not otherwise enhance performance (or even lead to lower performance when similar firms merge). Further, Sorenson shows that having close proximity in a network may lead to the diffusion of moderately complex knowledge, but that proximity does not facilitate diffusion when the knowledge is simple or highly complex.

A third theme relates to organizational learning, scientific discovery, and technological innovation. Building on the importance of interdependence among actors in the innovation process, Sorensen has developed models of organizational learning. These seek to explain the relationship between scientific research and technological innovation. He has emphasized how knowledge formation and diffusion is influenced by structural and behavioural properties in industries and regions (e.g. due to non-compete clauses). His analyses of patent citations and knowledge diffusion reveal that social proximity is most likely to be tied to citation under conditions of moderate knowledge complexity. When information is simple, social proximity is not needed as a mechanism of transmission; when it is very complex, transmission within an inventor's social circles tends to fail.

This essay provides a summary of the contributions and impact of Sorenson's work. We begin with a sketch of Sorenson's career path and research impact. In the next section, we present the three main contributions summarized above, highlighting theoretical, empirical and methodological advancements. We conclude by setting Sorenson's contributions in relation to the field of entrepreneurship.

\section{Olav Sorenson-a short biography}

Olav Sorenson received his bachelor's degree in Social Studies at Harvard College and his doctorate in Sociology at Stanford University, completing his Ph.D. studies in 1997. He was a student at Stanford during a particularly fertile intellectual period, studying with such luminaries in organization studies as Michael Hannan, James March, and Bill Barnett. Over the following years, he has held faculty positions at the University of Chicago, UCLA, London Business School, and University of Toronto. In 2009, he assumed his current position at Yale University, where he serves as the Frederick Frank '54 and Mary C. Tanner of Management and is the director of the core curriculum in the School of Management. He also holds an honorary doctorate from Aalborg University. Sorenson has been a senior or department editor for several leading management journals, including Management Science, Organization Science, and Research Policy. He co-founded the journal Sociological Science in 2013 and continues as one of its deputy editors. Sorenson has also been a member of several scientific and executive committees, including the Danish Research Unit on Industrial Dynamics (DRUID), the Kauffman Foundation's 'State of the Field' Initiative, and the Business Policy and Strategy Division of the Academy of Management. 
Sorenson is a well-cited researcher, especially considering his as of yet relatively young career in academia. A citation analysis reveals a remarkable level of intellectual influence for a scholar who received his Ph.D. less than 20 years ago. Sorenson has over 13,000 citations in Google Scholar (H-index 45) and over 4,000 in the Web of Science (H-index 28). Twentyfive of his articles have received over 100 citations in Google Scholar (see Table 1). Sorenson has obtained numerous accolades for his research and teaching, including awards for best papers from the Academy of Management, the European Academy of Management, the International Schumpeter Society, and the journal Research Policy. His excellence in teaching and advising has been recognized by the Rotman School of Management (Toronto) and the Anderson School of Management (UCLA). In 2012, he received the Carol and Bruce Mallen Award for his lifetime of scholarly contributions to the understanding of economics in the motion picture industry.

While past winners of the Global Award for Entrepreneurship Research have displayed comparable or even higher levels of influence measured on basic bibliometric indicators, few have reached this level at a relatively early career stage. Sorenson's achievement is especially impressive considering that his science is so closely aligned with the area of entrepreneurship and innovation, while the work of other winners has straddled domains that could be considered somewhat further afield, such as economic development or corporate strategy. Olav Sorenson's research has made strong contributions to both of the aforementioned domains.

Another valuable indicator of impact on the scientific community is the degree to which scientific findings spill over to related fields or schools of thought. In this context, we note that Sorenson's research is notable for its breadth of interdisciplinary and geographic influence. Considering the top ten publications that cite his highest ranked article on the spatial distribution of venture capital investments (Sorenson and Stuart 2001), we find two books on entrepreneurship, three books or papers in sociology, two papers on financial economics, two articles in research policy, and one article in economic geography. His research is interdisciplinary insofar as he has published extensively in sociology, management and economic geography, but also in mainstream economics and of late, in more general science journals. Sorenson has also collaborated with a wide range of scholars in different disciplines in Europe, Asia, and North America.
Sorenson has studied a range of industries and settings, as well as conducting population studies and cross-national research. Much of his scholarship has focused on the entertainment industries, notably Hollywood. He has also studied the venture capital industry in-depth and was among the first scholars to draw attention to the central importance of social networks in venture capital investments. Related to the venture capital studies are Sorenson's studies of biotechnology ventures, which he showed to be intimately related to physically proximate venture capital activities. Other settings include banking, footwear manufacturing, computer workstations, and the complete population of entrepreneurs and firms in Denmark.

The following sections will delve deeper into the specific scientific contributions of Sorenson. We find it important to state that underlying his entire research endeavour is the idea that entrepreneurship cannot be construed as a separate discipline (Sorenson and Stuart 2008). In the study of entrepreneurship, he says, there are no jointly held assumptions, theoretical paradigms, or clear distinctions from related schools of thought. Instead, Sorenson's explorations are based on the wish to understand particular, context-specific phenomena, and he has made ample use of this approach and implemented various disciplinary and methodological views. As mentioned above, this is reflected in his broad publishing strategy, where articles in sociology, management, economics and general science journals have spurred interdisciplinary research and helped to bridge separate domains.

\section{The geography of entrepreneurial activity}

One of Sorenson's earliest and most sustained streams of research has been on the geography of entrepreneurial activity. His scholarship engages a central question in this literature: why do industries exhibit spatial agglomeration, whereby organizations of a particular type tend to cluster more in some geographic areas than in others, and what, in turn, are the effects of spatial agglomeration on entrepreneurs and regions? Previous accounts of agglomeration emphasized performance advantages among mature enterprises that helped to explain sustained patterns of geographic clustering. Dating back to Alfred Weber (1929), classic location theory points to two sources of advantage in particular: (a) some geographic locales offer more convenient access to inputs 
Table 1 Olav Sorenson's most cited publications

Publication

Google Scholar

Citations
Web of Science Citations

'Syndication Networks and the Spatial Distribution of Venture Capital Investments' (w/ T. Stuart), 1634 590 American Journal of Sociology, 2001, 106: 1546-1588.

'Technology as a Complex Adaptive System: Evidence from Patent Data' (w/ L. Fleming*), 2001a, 1021 Research Policy, 30: 1019-1039.

'The Social Structure of Entrepreneurial Activity: Geographic Concentration of Footwear

Production in the United States' (w/ P. Audia), American Journal of Sociology, 2000, 106: 424-462.

'Science as a Map in Technological Search' (w/ L. Fleming*), 2004, Strategic Management Journal, 25: 909-928.

'The Geography of Opportunity: Spatial Heterogeneity in Founding Rates and the Performance of 860 Biotechnology Firms' (w/ T. Stuart*), 2003, Research Policy, 32: 229-253.

'Complexity, Networks and Knowledge Flow' (w/ J. Rivkin and L. Fleming), 2006, Research Policy, 35: 994-1017

'Finding the Right Mix: Franchising, Organizational Learning, and Chain Performance' (w/ J. Sørensen), 2001, Strategic Management Journal, 22: 713-724.

'Liquidity Events and the Geographic Distribution of Entrepreneurial Activity' (w/ T. Stuart*), 2003, Administrative Science Quarterly, 48: 175-201.

'Social Networks and Industrial Geography,' 2003, Journal of Evolutionary Economics, 13: 513-527.

'Bringing the Context Back In: Settings and the Search for Syndicate Partners in Venture Capital Investment Networks' (w/ T. Stuart), 2008, Administrative Science Quarterly, 53: 266-294.

'Science and the Diffusion of Knowledge' (w/ L. Fleming), 2004, Research Policy, 33: 1615-1634.

'Strategic Networks and Entrepreneurial Ventures' (w/ T. Stuart*), 2007, Strategic Entrepreneurship Journal, 1: 211-227.

'Venture Capital, Entrepreneurship, and Economic Growth' (w/ S. Samila*), 2011, Review of Economics and Statistics, 93: 338-349.

'Home Sweet Home: Entrepreneurs' Location Choices and the Performance of their Ventures' (w/ M. Dahl*), 2012, Management Science, 58: 1059-1071.

'Interdependence and Adaptability: Organizational Learning and the Long-Term Effect of Integration,' 2003, Management Science, 49: 446-463.

'Letting the Market Work for You: An Evolutionary Perspective on Product Strategy,' 2000, Strategic Management Journal, 21: 577-592

'Social Structure and Exchange: Self-Confirming Dynamics in Hollywood' (w/ D. Waguespack), 2006, Administrative Science Quarterly, 51: 560-589.

'The Embedded Entrepreneur' (w/ M. Dahl*), 2009, European Management Review, 6: 172-181.

'The Red Queen in Organizational Creation and Development' (w/ W. Barnett*), 2002, Industrial and Corporate Change, 11: 289-325.

'Social Networks and Entrepreneurship' (w/ T. Stuart*), 2005, Handbook of Entrepreneurship Research, 233-252.

'Non-Compete Covenants: Incentives to Innovate or Impediments to Growth' (w/ S. Samila*), 2011, Management Science, 57: 425-438.

'Brokers and Competitive Advantage' (w/ M. Ryall), 2007, Management Science, 53: 566-583.

'The Dangers of Modularity' (w/ L. Fleming*), 2001b, Harvard Business Review, 79: 20-21

803

465

447

333

319

318

303

296

262

221

208

200

363

860

288

175

142

151

114

110

75

80

108

97

92

77

183

66

162

44

142

57

127

The list includes publications with at least 100 citations in Google Scholar. Citation counts were calculated on May 5, 2018. *Indicates first author on publication where Sorenson is not the lead author

needed by an industry or stronger local demand for a product or service and (b) scale economies tend to result from spatial agglomeration, such that similar enterprises benefit from their proximity, in terms of minimizing transportation or transaction costs, attracting a larger and better-trained pool of labour, and enjoying knowledge spillovers. In a series of pioneering articles, Sorenson has challenged these basic assumptions, differentiating the effect of geography on new - rather than mature-ventures and calling attention to the role of space in structuring social-rather than mere exchange-relationships. 
Sorenson initiated this argument in 2000, with a now famous article in the American Journal of Sociology. Along with his co-author Pino Audia, he pointed out that location theory was theoretically and empirically unsatisfactory, because the same factors that could generate performance advantages were also likely to lead to intense competition among geographically clustered firms. To address this contradiction, the authors distinguished the process of business founding from business failure. In the former case, entrepreneurs benefitted from spatial agglomeration because it exposed them to spillover effects and allowed them to draw on local networks of friends and acquaintances with expertise in an industry. For instance, nascent entrepreneurs might serve an apprenticeship with an established owner, read accounts of successful businesses in local publications, take technical courses at a local college, and attend trade fairs or 'networking' events (Aldrich and Ruef 2006). In the latter case, established firms suffered from spatial agglomeration because it exposed them to more intense competition and higher rates of failure than isolated firms. Examining systematic data on all producers of footwear in the USA over a 50-year period, Sorenson and Audia provided the first empirical support for these hypotheses, showing that the founding rates for new manufacturing plants increased with spatial agglomeration, as did the failure rates for existing plants.

This early work was soon extended in a series of articles on the geographic distribution of venture capital, an industry known for its very high level of spatial agglomeration in regions such as Silicon Valley and San Diego. Sorenson's research with Audia assumed that spatial constraints affected patterns of interactions among entrepreneurs, but did not have direct data on social networks. Working with Toby Stuart, another leading entrepreneurship scholar, Sorenson documented how interfirm networks among venture capitalists (VC's) contributed to the geographic concentration of VC investments. In his most highly cited article to date, appearing in the American Journal of Sociology, Sorenson and Stuart (2001) show that the probability that a VC invests in a new venture declines sharply with distance, as assessed in both spatial terms and considerations of industry similarity. They then theorize and empirically investigate the conditions under which the 'spatial reach' of VC's might increase, finding that the range of network contacts (via syndicated investments) and reputation of firms are crucial drivers of this process. Another article traces the impact of $\mathrm{VC}$ investments on spatial agglomeration in the biotechnology sector. Stuart and Sorenson (2003) show that the geographic clustering of biotech founding is conditioned by proximity to VC's and other biotech firms, but that this effect declines with industry maturation. A third paper from the project brought the study of geographic opportunity and entrepreneurship full circle, investigating how liquidity events (e.g. initial public offerings and the acquisition of early-stage technology companies) affected founding activity in nearby geographic areas. Writing in the Administrative Science Quarterly, Stuart and Sorenson (2003) documented the location-specific impact of these events, which may trigger the founding of new firms when high-level employees are able to 'cash in' on stock options to start their own companies or serve as social proof for nascent entrepreneurs hoping to emulate the success of proximate peers.

While Sorenson's research on the geography of entrepreneurship in the early 2000's focused empirically on firm-level factors and inter-organizational networks, the underlying mechanisms were frequently theorized at the level of individual entrepreneurs and their experiences. His recent work has increasingly pushed entrepreneurship scholars to test spatial models at the micro-level. For instance, collaborating with Michael Dahl, Sorenson has analysed the effect of residential tenure among entrepreneurs on the performance of their start-ups. One set of life course theories holds that entrepreneurs select business locations in order to spend time (or work) with friends and family. This implies a lower threshold for start-up performance among entrepreneurs with this 'home region' bias (Gimeno et al. 1997).

Another theory holds that residential tenure translates into a deeper repository of local knowledge and social ties. This implies an increase in start-up performance when entrepreneurs have lived in an area for an extended period of time. Analysing a comprehensive database of start-ups in Denmark, Dahl and Sorenson (2012) consistently find payoffs to entrepreneurial performance when entrepreneurs have long-standing roots in a region.

Sorenson's research has not just considered the effect of geography on entrepreneurs, but also the role of entrepreneurship in regional economic development. Working with Sampsa Samila, he has documented a likely causal link between the supply of venture capital in a region and a variety of outcomes, including firm starts, employment and payroll (Samila and Sorenson 
2011a, b). This causal link is not necessarily a function of the investments provided by VC's - even in Silicon Valley, fewer than $4 \%$ of new companies are funded by venture capital (Samila and Sorenson 2011b, p. 338). But, as Sorenson has documented in much of his research, VC's are also a source of networks that connect entrepreneurs and firms, while remaining geographically localized. Indeed, an apt summary of this work on the geography of entrepreneurship can be found in his article in the Journal of Evolutionary Economics: 'social networks play an important role in the entrepreneurial process, and in doing so also significantly influence the dynamics of the geographic dispersion of industries' (Sorenson 2003b, p. 524).

Traditionally, most studies of regions and entrepreneurship have treated geographic areas as independent units within which firms and institutions create more or less advantageous habitats for existing firms and for entrepreneurs. Sorensen's work has pioneered new ways of thinking about regions as habitats for entrepreneurs. By treating geography as a continuous variable, he helps us view these entrepreneurial habitats not as islands, but rather as geographic units within an interconnected system. His work has also unearthed how entrepreneurial relations in geographical space differ from relations in social space by showing that physical distance across regions 'shrinks' for entrepreneurs when social proximity is considered.

\section{Social capital and entrepreneurial activity}

This leads us to a second major research stream in the work of Sorenson, which concerns the relationship of social capital to entrepreneurial activity and innovation. Studies of social capital often subsume the analysis of social networks, but also bring in more general considerations of interpersonal trust and trust in institutions (Kwon et al. 2013). By the same token, Sorenson's research in this area began by considering how social networks affect economic geography, but soon moved to a set of broader considerations.

Writing in the Strategic Entrepreneurship Journal, Stuart and Sorenson (2007) recognized numerous studies that highlight the centrality of networks in the entrepreneurial process. At the same time, few studies had dealt rigorously with the problem of endogeneity, insofar as entrepreneurs form networks and place trust in others on a strategic basis, thereby complicating efforts to trace causal effects from social capital to entrepreneurial outcomes. It has been noted that early studies merely describe the structure and workings of entrepreneurial networks, but not their origins or formation process (Hochberg et al. 2007). Sorenson and colleagues pointed out such avenues as fruitful for further research. Indeed, Stuart and Sorenson laid out a pioneering agenda to deal with this issue, including methodological approaches to the endogeneity issue (e.g. experiments and quasi-statistical methods) and a substantive shift in analytical emphasis, from an exclusive focus on network 'effects' to considerations of network evolution and origins.

Sorenson has pursued this agenda empirically through a number of ground-breaking studies. Working with David Waguespack, he analysed the effect of repeated collaborations between film distributors and the teams that produce movies. While numerous studies in sociology have touted the benefits of such socially embedded transactions, Sorenson and Waguespack (2006) show that this effect is illusionary in the case of the Hollywood film industry. Distributors favour films that involve key production personnel with whom they have worked in the past and allocate additional resources (promotion effort and choice opening dates) to them. Once Sorenson and Waguespack accounted for this process of resource allocation, there was no beneficial effect from repeated collaboration. The same selffulfilling dynamic may hold more widely in entrepreneurial settings. When investors and entrepreneurs share a history of successful interactions, the investors may offer more funding in exchange for a smaller equity stake or less onerous terms. This can introduce a putative positive association between repeat collaboration and start-up performance, even though there is no causal relationship once the process of investment is considered as a mediating variable (Stuart and Sorenson 2007).

In a related line of research, Sorenson considers the impact of social relationships on knowledge diffusion, with a particular focus on the implications for the process of innovation. Collaborating with Lee Fleming and Jan Rivkin, he has studied prior art citations of patents as evidence of knowledge diffusion. They consider the social proximity of inventors via positions in a collaboration network, investigating when closeness to a knowledge source contributes to the citation of prior art (Sorenson et al. 2006). Their analysis of utility patent citations reveals that social nearness is most likely to be tied to citation under conditions of moderate knowledge 
complexity. When information is simple, social proximity is not needed as a mechanism of transmission; when it is very complex, transmission within an inventor's social circles tends to fail.

A central facet of social capital theory is that networkbased relationships can bring both advantages and disadvantages, by increasing the flow of information within the network while constraining attention to actors with whom a focal actor is already in direct contact, thus highlighting the risk of being 'over-embedded' in a network. Sorenson's work on the implications of social capital for innovation and entrepreneurship has attended to the potential risk of such over-embeddedness in the context of interorganizational relationships. In a joint paper with Michelle Rogan, he examined the effects of advertising agencies having common clients with other agencies on the likelihood that two agencies would merge, and whether the merger would be financially successful or not (Rogan and Sorenson 2014). While having common clients was found to be a strong predictor of two agencies' merging, Rogan and Sorenson found that the joint performance of the merged organization declined when sharing common clients, both by losing clients and by selling less to the clients they retained.

Sorenson has also developed the organizational implications of network relationships in terms of 'interorganizational brokerage' whereby a 'broker' assumes an intermediating position between two (or more) parties. In a formal modelling exercise, Ryall and Sorenson (2007) show that brokers can enjoy an advantage, but only if (1) they do not face substitutes, either for the connections they offer or the value they can create, (2) they intermediate more than two parties, and (3) interdependence does not lock them into a particular pattern of exchange. These relationships depend on the assumption that connections between actors are exogenous and not voluntarily chosen. If actors form relationships on the basis of their expectations of the future value of those relations, then the potential profitability of having a brokerage position only arise under strict assumptions. In a more recent overview article, Sorenson and Rogan (2014) discuss the role of interorganizational relationship and the extent to which organizations - as opposed to organizational members like employees and owners - control such contacts. Arguing that individuals' control of the value in network relationships are becoming increasingly common as firms' competitive resources depend more on human and social capital resources than on physical resources (like money and machinery), Sorenson and Rogan (2014) outline conditions under which these network relationships are more or less likely to be controlled by employing organizations or their members, with implications for future research on such relationships and their consequences.

\section{Organizational learning, scientific discovery and technological innovation}

Sorenson's work on social capital during the second phase of his career coincided with a third major research stream, focusing on processes of entrepreneurial learning and innovation, or phrased in a different manner, on organizational learning, scientific discovery, and technological innovation. In some respects, this interest was the most direct reflection of his time as a Ph.D. student at Stanford, when Sorenson was exposed to the evolutionary paradigm of Mike Hannan and Bill Barnett, as well as the perspective on organizational learning pioneered by James March. In an early publication, Sorenson collaborated with Barnett to develop the evolutionary idea of a 'Red Queen' effect in the founding and growth of small businesses - i.e. a self-reinforcing dynamic in which competition triggers learning and adaptation, which in turn triggers more competition (Barnett and Sorenson 2002). Around the same time, Sorenson was articulating his own distinctive approach to the evolution of learning and innovation.

In a widely cited article in Management Science, Sorenson (2003a) revitalized the concept of internal interdependence as an essential feature of organizational learning and innovation. In stable environments, Sorenson noted that a high level of interdependence in decision-making is generally problematic, limiting the ability of managers to learn from their own experience. However, increases in environmental volatility (e.g. disagreements over technology standards or instability in sales) could attenuate the downside of interdependence, as managers in firms with high levels of integration were more likely to learn from other units and production facilities within their companies. Sorenson found support for his theory of organizational learning in an analysis of the performance of workstation manufacturers over a 17-year period. The findings also dovetailed with his earlier research, with Lee Fleming, on the limits of modularity in product design (Fleming and Sorenson 2001a, b). 
Sorenson has since produced a string of research on the role of organizational learning in divisionalized and multi-product organizations. One early paper examined the trade-off between maintaining a large product portfolio to serve a broad customer base versus cutting product lines with lower performance in order to increase overall profitability (Sorenson 2000a, b). Analysing the same data on computer workstations in the USA, Sorenson found product variety to be less valuable when the total number of products on the market increases. Furthermore, cutting down on the number of product lines improved organizational survival, but less so when sales were highly variable. Another paper examined the mix of company-owned establishments versus franchise establishments in franchise chains, arguing that while franchised establishments provide better opportunities to learn through experimentation, company-owned establishments provide better opportunities to diffuse new procedures and enforce operating standards throughout the organization (Sorenson and Sørensen 2001). Analyses of restaurant chains in the USA reveal the advantages of experimentation in franchised establishments to be more pronounced for geographically dispersed franchise chains, while the advantages of information flow and standardization in company-owned establishments are more pronounced for franchise chains operating in fewer geographical areas. Sorenson's work has also attended to innovation processes in large firms. A paper with Markus Reitzig studied innovation proposals inside a multinational consumer goods firm, finding that evaluators of such proposals are biased in favor of ideas submitted by individuals that work in the same division and facility (Reitzig and Sorenson 2013). Recently, Natividad and Sorenson (2015) also showed how adverse effects experienced by one line of business can affect other lines of business in divisionalized firms. Studying the US film industry, Natividad and Sorenson found that movie theater releases in periods of unexpected volatility tend to lower movie theater sales as well as sales from concurrent home video releases, which represent a different business line. A causal mechanism underlying the diffusion of adverse effects across business lines seemed to be that managers often diverted resources away from the home video division by trying to counter the threat to lower sales in the movie theater release by intensifying advertising and promotion of their films in theaters.

More recently, Sorenson has expanded these insights on interdependence and innovation to consider their implications for the evolution of scientific discoveries. In another joint paper with Fleming, he provided one of the first rigorous empirical inquiries into the process of 'translation'-i.e. how basic scientific research is converted into technological innovation (Sorenson and Fleming 2004). The paper examines the rate of citation for patents based on published scientific and nonscientific materials, finding that published knowledge served as a catalyst for innovation, increasing both the rate and scope of citation relative to patents that were based on unpublished (e.g. proprietary) materials. Sorenson has continued this line of research into barriers and catalysts affecting scientific accumulation and innovation, including research on scientific authorship (Lerchenmueller and Sorenson 2016), gender disparities in the life sciences (Lerchenmüller et al. 2018), promotions (Lerchenmueller and Sorenson 2018), inventorship (Jensen et al. 2018), explanations of scientific misconduct (Baron et al. 2016), and how noncompete clauses affect entrepreneurship and job creation (Samila and Sorenson 2011a, b).

\section{Summary and conclusions}

This article has reviewed the academic contributions of Olav Sorenson. In this final section, we relate these contributions to central themes, research puzzles, and public policy discussions in entrepreneurship research, for which he has been awarded the 2018 Global Award for Entrepreneurship Research. Since its establishment in 1996, the prize has been bestowed on leading researchers such as Philippe Aghion, William Baumol, Kathleen Eisenhardt, Marianne Feldman, and Sidney Winter. ${ }^{1}$ Sorenson compares well with this group of prominent scientists. The prize statutes state that a worthy winner must first and foremost have contributed with original and influential research. 'Originality' here means solving principal research puzzles, building theoretical foundations or fostering new methodological approaches. The impact these contributions may have on other researchers-and thus their influence on

\footnotetext{
${ }^{1}$ The partners behind the Award are the founder (Swedish Entrepreneurship Forum), the co-founder (Research Institute of Industrial Economics, IFN), the sponsor (Sweden's Innovation Agency, VINNOVA), and the donor (Stockholms Köpmansklubb, since 2016). The prize consists of 100,000 euro and a statuette by the internationally renowned sculpture Carl Milles, called the "Hand of God". The Prize Committee follows similar procedures as the Nobel committee.
} 
subsequent research-is of essence. Sometimes this is achieved simply by carving out well-received academic studies that many other scholars take notice of and build upon. Sometimes, this is achieved through the organization of large research programs and teams of investigators. Influence may also come through the promotion of entrepreneurship as a research field, e.g. through the creation of wide-spanning datasets, or starting influential journals. In addition, development of entrepreneurship education at an academic level or substantial impact on individuals, entrepreneurs, firms, policy makers or society at large may be grounds for selection for the prize. Sorenson fulfils several of these criteria. He has been influential in his view on the field of entrepreneurship as intermingling with other disciplines such economics, organizational behaviour, strategy, marketing, finance, sociology, business history, and geography, and in his original insights in three specific areas and their relationship to entrepreneurial activity: geography, social capital, and learning and innovation. His research is highly interdisciplinary, and conjoins discernments from his own main field of sociology, with that of economics, economic geography, and management. In this way, he lives up to the standards of not treating entrepreneurship as a coherent discipline, but one that learns from other schools, and by giving back to these schools and disciplines.

As we have seen in our review, Sorenson has also moved us closer to solutions for several puzzles related to the themes above. Together with colleagues he has shown how social networks and personal affiliations set the conditions for the location choices of firms as well as venture capitalists, in turn affecting knowledge flows and resource access. For instance, by distinguishing between types of firms - mature versus young - he has found a resolution for a key paradox of spatial agglomeration.

Sorenson's studies have attended to multiple levels of analyses and speak to diverse audiences. Indeed, the broad scope of the prize and the domain of entrepreneurship research highlights that entrepreneurship can be studied at various levels of analysis - individuals, teams, projects, organizations, regions, industries, nations, and the macroeconomic level. Also, Sorenson has strived for more 'cumulative' research in the social sciences, arguing that management research in particular should strive for more theory testing and other forms of empirical research, such as replications (Shi et al. 2017), rather than having every paper develop a 'novel' theory
(Sorenson 2008). Discussing entrepreneurship research in particular, Sorenson and Stuart (2008) argue for careful empirical explorations of particular phenomena using tools and methods established in neighbouring disciples, rather than seeking to develop grand theories of entrepreneurship.

In terms of methodological advancements, Sorenson has sought to propagate the use of more formal approaches (mathematical or computational models, formal logic) to develop management theory (Adner et al. 2009; Sorenson 2002). In a special issue on the topic appearing in the Academy of Management Review, Sorenson and his co-authors argue that verbal theorizing cannot provide the same consistency and precision or reveal unexamined assumptions. They present examples of when formal approaches have performed well and yielded useful insights. Sorenson himself has developed formal models and simulation studies (Ryall and Sorenson 2007). Recently, he has also promoted and adopted methods to address the highly endogenous nature of social networks (e.g. experiments and quasiexperimental methods), as well as shifting attention from various forms of network 'effects' to considerations of network evolution and origins. His research on entrepreneurship and economic growth (Samila and Sorenson 2011a, b) and other streams of research bear witness to his attempts to infuse more causal evidence into entrepreneurship research.

Sorenson's work speaks to the process of innovation and growth in the economy and is therefore of upmost importance to managers as well as policy makers. Throughout the world, policy makers increasingly turn to entrepreneurship as a potential cure for economic maladies. Sorenson's key to understanding processes of economic advancement lies in mapping out the details of networks and social relations, the process by which networks form shape the initial phases of innovation processes, and are important determinants for knowledge and resource flows (Sorenson 2018). Consequently, understanding social relations is a crucial channel for coming to grips with the very details of innovation in an economy. Sorenson's findings resonate well with an evolutionary view of economic development (Nelson and Winter 1982) in that the tension between the creation of variety (the invention process), the selection process, and the retention created in the system by the development of routines speaks to the role of knowledge flows. Actors, networks or systems who do not - through learning — have the capability to adapt 
their routines, products and processes to compete with innovations in their fields of activities (markets) have to close down or restructure. Innovations, following Schumpeter (1934), can be characterized as novel and creative combinations of knowledge which may be recently acquired as well as long-known. Innovations destroy existing structures and create something new on the ruins of the old. It is this very process of network formation and learning which is highlighted by Sorenson's contributions.

In this vein, he and his co-authors (Acs et al. 2008) discuss how economic development that concentrates on entrepreneurship is 'a fundamentally different phenomenon' than traditional ways of viewing innovation and change, and that new policies need to be implemented at local, state, and regional levels. One of the truly imperative contributions that Sorenson has given to policy makers is the assurance that findings are based on pointed research questions, meticulously thought-out methodology, diligent data collection and analysis, and a clear foundation in related literature. Another contribution is to public policy in entrepreneurial finance. In an article published in Science, Sorenson and his coauthors (2016) showed that crowdfunding is more important for regions with less developed venture capital markets.

For managers, the findings on the role of geography highlighted in this paper speak to young and mature firms alike, as well as to investors. Based on analyses of firm's competitive conditions, Sorenson argued early that strategic decisions should be seen as 'quasi-experimentation' in that it is the process of relevant knowledge acquisition that enables suitable decision making (Sorenson 2000a, b; Sorenson 2003a, b, c). As actors' performance improves with experience, guided and intentional experimentation can help firms learn more effectively. Learning curves can be influenced through a better understanding of the logic of knowledge generation. Sorenson's studies of experimentation, knowledge acquisition, and decision makingand how they are related to innovation and performance - represent a notable contribution to entrepreneurship studies. Along with his foundational work on the social and spatial boundaries of entrepreneurial relationships, this scholarship makes Olav Sorenson a very apt recipient of The Global Award for Entrepreneurship Research.

Acknowledgments This paper has benefited by helpful comments and advice from Pino Audia, Tünde Caerpes, Michael Dahl,
Sarah Jack, and David Waguespack. Sebastian Ekberg and Michel Laufer provided research assistance. All errors and omissions remain the responsibility of the authors.

Open Access This article is distributed under the terms of the Creative Commons Attribution 4.0 International License (http:// creativecommons.org/licenses/by/4.0/), which permits unrestricted use, distribution, and reproduction in any medium, provided you give appropriate credit to the original author(s) and the source, provide a link to the Creative Commons license, and indicate if changes were made.

\section{References}

Acs, Z.J., E.L. Glaeser, R.E. Litan, L. Fleming, S.J. Goetz, W.R. Kerr, S. Klepper, S.S. Rosenthal, O. Sorenson and W.C. Strange. (2008). Entrepreneurship and urban success: toward a policy consensus. Available at SSRN: https://ssrn. com/abstract $=1092493$.

Adner, R., Polos, L., Ryall, M., \& Sorenson, O. (2009). The case for formal theory. Academy of Management Review, 34(2), 201-208.

Aldrich, H., \& Ruef, M. (2006). Organizations evolving. London: Sage.

Barnett, W. P., \& Sorenson, O. (2002). The Red Queen in organizational creation and development. Industrial and Corporate Change, 11(2), 289-325.

Baron, J., King, M., \& Sorenson, O. (2016). S/he blinded me with science: the sociology of scientific misconduct. In D. Palmer, R. Greenwood, \& K. Smith-Crowe (Eds.), Organizational wrongdoing: key perspectives and new directions (pp. 176202). Cambridge: Cambridge University Press.

Dahl, M. S., \& Sorenson, O. (2012). Home sweet home: entrepreneurs' location choices and the performance of their ventures. Management Science, 58(6), 1059-1071.

Fleming, L., \& Sorenson, O. (2001a). The dangers of modularity. Harvard Business Review, 79(8), 20-21.

Fleming, L., \& Sorenson, O. (2001b). Technology as a complex adaptive system: evidence from patent data. Research Policy, 30(7), 1019-1039.

Gimeno, J., Folta, T. B., Cooper, A. C., \& Woo, C. Y. (1997). Survival of the fittest? Entrepreneurial human capital and the persistence of underperforming firms. Administrative Science Quarterly, 42(4), 750-783.

Hochberg, J., Ljungqvist, A., Lu, Y. (2007). Whom you know matters: Venture capital networks and investment performance. Journal of Finance 62(1), 251-301

Jensen, K., Kovács, B., \& Sorenson, O. (2018). Gender differences in obtaining and maintaining patent rights. Nature Biotechnology, 36(4), 307-309.

Kwon, S.-W., Heflin, C., \& Ruef, M. (2013). Community social capital and entrepreneurship. American Sociological Review, 78(6), 980-1008.

Lerchenmueller, M. J., \& Sorenson, O. (2016). Author disambiguation in PubMed: evidence on the precision and recall of authority among NIH-funded scientists. PLoS One, 11(7), https://doi.org/10.1371/journal.pone.0158731. 
Lerchenmueller, M. J., \& Sorenson, O. (2018). The gender gap in early career transitions in the life sciences. Research Policy, 47(6), 1007-1017.

Lerchenmüller, C., Lerchenmueller, M. J., \& Sorenson, O. (2018). Long-term analysis of sex differences in prestigious authorships in cardiovascular research supported by the National Institutes of Health. Circulation, 137(8), 880-882.

Natividad, G., \& Sorenson, O. (2015). Competitive threats, constraint, and contagion in the multiunit firm. Organization Science, 26(6), 1721-1733.

Nelson, R., \& Winter, S. (1982). An evolutionary theory of economic change. Cambridge, MA: Belknap Press.

Reitzig, M., \& Sorenson, O. (2013). Biases in the selection stage of bottom-up strategy formulation. Strategic Management Journal, 34(7), 782-799.

Rogan, M., \& Sorenson, O. (2014). Picking a (poor) partner: a relational perspective on acquisitions. Administrative Science Quarterly, 59(2), 301-329.

Ryall, M. D., \& Sorenson, O. (2007). Brokers and competitive advantage. Management Science, 53(4), 566-583.

Samila, S., \& Sorenson, O. (2011a). Noncompete covenants: incentives to innovate or impediments to growth. Management Science, 57(3), 425-438.

Samila, S., \& Sorenson, O. (2011b). Venture capital, entrepreneurship, and economic growth. The Review of Economics and Statistics, 93(1), 338-349.

Schumpeter, J. A. (1934). The theory of economic development. Cambridge: Harvard University Press.

Shi, Y., Sorenson, O., \& Waguespack, D. M. (2017). Temporal issues in replication: the stability of centrality-based advantage. Sociological Science, 4, 107-122.

Sorenson, O. (2000a). The effect of population-level learning on market entry: the American automobile industry. Social Science Research, 29(3), 307-326.

Sorenson, O. (2000b). Letting the market work for you: an evolutionary perspective on product strategy. Strategic Management Journal, 21(5), 577-592.

Sorenson, O. (2002). Interorganizational complexity and computation. In J. A. Baum (Ed.), Blackwell companion to organizations (pp. 664-685). Oxford: Blackwell.
Sorenson, O. (2003a). Interdependence and adaptability: organizational learning and the long-term effect of integration. Management Science, 49(4), 446-463.

Sorenson, O. (2003b). Social networks and industrial geography. Journal of Evolutionary Economics, 13(5), 513-527.

Sorenson, O. (2003c). Strategy as quasi-experimentation. Strategic Organization, 1(3), 337-343.

Sorenson, O. (2008). The tyranny of theory. In D. Barry, \& H. Hansen (Eds.), SAGE handbook of new approaches in management and organization (pp. 449-450). London: SAGE. https://doi.org/10.4135/9781849200394.

Sorenson, O. (2018). Innovation policy in a networked world. Innovation Policy and the Economy, 18(1), 53-77.

Sorenson, O., \& Fleming, L. (2004). Science and the diffusion of knowledge. Research Policy, 33(10), 1615-1634.

Sorenson, O., \& Rogan, M. (2014). (When) do organizations have social capital? Annual Review of Sociology, 40(1), 261-280.

Sorenson, O., \& Sørensen, J. B. (2001). Finding the right mix: franchising, organizational learning, and chain performance. Strategic Management Journal, 22(6-7), 713-724.

Sorenson, O., \& Stuart, T. E. (2001). Syndication networks and the spatial distribution of venture capital investments. American Journal of Sociology, 106(6), 1546-1588.

Sorenson, O., \& Stuart, T. E. (2008). Entrepreneurship: a field of dreams? Academy of Management Annals, 2(1), 517-543.

Sorenson, O., \& Waguespack, D. M. (2006). Social structure and exchange: self-confirming dynamics in Hollywood. Administrative Science Quarterly, 51(4), 560-589.

Sorenson, O., Rivkin, J. W., \& Fleming, L. (2006). Complexity, networks and knowledge flow. Research Policy, 35(7), 9941017.

Stuart, T., \& Sorenson, O. (2003). The geography of opportunity: spatial heterogeneity in founding rates and the performance of biotechnology firms. Research Policy, 32(2), 229-253.

Stuart, T. E., \& Sorenson, O. (2007). Strategic networks and entrepreneurial ventures. Strategic Entrepreneurship Journal, 1(3-4), 211-227.

Weber, A., (1929). Theory of the location of industries [translated by C.J. Friedrich from Weber's 1909 book]. Chicago: The University of Chicago Press. 